\title{
Establishment and characterization of a novel cell line (cc-006cpm8) of moderately/poorly differentiated colorectal adenocarcinoma derived from a primary tumor of a patient
}

\author{
$\mathrm{XIA} \mathrm{CHU}^{1 *}$, YIQI XUE ${ }^{1 *}, \mathrm{XINYING} \mathrm{HUO}^{2 *}$, JINGSUN WEI $^{2 *}$, YUETONG CHEN $^{2}$, RONGBO HAN $^{2,3}$, \\ HONG CHEN $^{2}$, XINYU SU ${ }^{2}$, HONGHONG ZHANG ${ }^{2}$, YANG GONG ${ }^{2}$ and JINFEI CHEN ${ }^{1,2,4}$
}

${ }^{1}$ Cancer Center, Taikang Xianlin Drum Tower Hospital, Nanjing University; ${ }^{2}$ Department of Oncology, Nanjing First Hospital, Nanjing Medical University, Nanjing, Jiangsu 210046; ${ }^{3}$ Department of Oncology, Taixing People's Hospital,

Taixing, Jiangsu 225400; ${ }^{4}$ Collaborative Innovation Center for Cancer Personalized Medicine,

Nanjing Medical University, Nanjing, Jiangsu 210046, P.R. China

Received July 6, 2018; Accepted May 14, 2019

DOI: 10.3892/ijo.2019.4806

\begin{abstract}
In the present study, the cc-006cpm8 novel colon cell line was established from a sample of right colorectal adenocarcinoma obtained from a woman with liver metastasis. It was possible to culture this cell line for $\geq 100$ passages in vitro with vigorous growth. Morphologically, the cells grew as several layers with tight adhesion to the surface of the culture plate. The morphological, immunological and ultrastructural features of these cells suggested their epithelial origin. The characterization of this cell line indicated a doubling time of $27 \mathrm{~h}$, a colony forming efficiency of $73.2 \%$ in semisolid media and a plate efficiency of $66.5 \%$ in liquid culture. The modal number of chromosomes was 50. In vivo, the cc-006cpm8 cells underwent tumorigenesis in all nude mice used. Immunohistochemical analysis demonstrated
\end{abstract}

Correspondence to: Professor Jinfei Chen, Cancer Center, Taikang Xianlin Drum Tower Hospital, Nanjing University, 188 Lingshan North Road, Qixia, Nanjing, Jiangsu 210046, P.R. China

E-mail: jinfeichen@sohu.com

*Contributed equally

Abbreviations: CRC, colorectal cancer; MMR, mismatch-repair; SNP, single nucleotide polymorphism; InDel, insertion-deletion; SNV, single nucleotide variant; STR, short tandem repeat; CEA, carcinoembryonic antigen; EMA, epithelial membrane antigen; CDX2, caudal type homeobox transcription factor 2; PDT, population doubling time; PCR, polymerase chain reaction; IDT, Integrated DNA Technologies; CCTCC, China Center for Type Culture Collection; TM, transmembrane; ccRCC, clear cell renal cell carcinoma; PDAC, pancreatic ductal adenocarcinoma; SLE, systemic lupus erythematosus; ANSI, American National Standards Institute; ATCC, American Type Culture Collection; DSMZ, Deutsche Sammlung von Mikroorganismen und Zellkulturen.

Key words: cell line, colorectal cancer, mismatch-repair, gene alterations, whole exome sequence that mutS homolog 2 (MSH2) and MSH6 were expressed; however, mutL homolog 1 and postmeiotic segregation 2 were downregulated in cc-006cpm8 cells. To determine the mutation profile of the cell line analyzed, exome capture DNA sequencing was performed. The results revealed 20 hypermutated exons comprising single nucleotide polymorphisms, and insertion and deletions (InDels), including single nucleotide variants of mucin $(M U C) 19$, MUC16, MUC12, filaggrin and AHNAK nucleoprotein 2, and InDels of $\beta$ defensin-126, microRNA-3665, WNK lysine deficient protein kinase 1 and SLAIN motif-containing protein 1 . In addition, commonly mutated genes in colorectal cancer and exon mutations of genes in cc-006cpm8 cells were analyzed, including adenomatous polyposis coli, tumor protein p53, Drosophila mothers against decapentaplegic 4, phosphatidylinositol-4,5-bisphosphate 3-kinase catalytic subunit $\alpha$ and Kirsten rat sarcoma, and genes associated with the DNA mismatch repair pathway were investigated.

\section{Introduction}

Generally, colorectal cancer (CRC) is the third most common cause of morbidity worldwide and the fourth leading cause of cancer-associated mortality (1). Globally, CRC is the third most common type of cancer among men $(746,000$ cases, $10.0 \%$ of total cancer cases) and the second among women (614,000 cases, $9.2 \%$ of total cancer cases) $(2,3)$. The morbidity and mortality rates of CRC exhibit notable geographical variation. CRC is also a main cause of cancer-associated mortality among developed countries. In 2012, 1,4000,000 patients succumbed to mortality due to cancer, of which 693,900 cases were associated with CRC (4); however, the morbidity and mortality rates of CRC were markedly lower among less developed countries. In the USA, $\sim 132,700$ individuals were diagnosed with CRC in 2015 and $\sim 49,700$ patients with CRC succumbed in 2015 (5). CRC is a multifactorial disease with a complex multistep process of development associated with genetic background, environmental factors and numerous genetic alterations (6). The risk factors of CRC include a high fat 
diet, high adiposity index, smoking, alcoholism, stress, inflammatory bowel diseases, and the predisposition to polyp formation and hereditary components, which comprise hereditary nonpolyposis CRC (6-10).

It is necessary to understand the molecular mechanisms underlying the tumorigenesis of CRC, which may assist in CRC characterization, the prognosis and stratification of patients, and the development of personalized treatment $(11,12)$. The in vitro culture of tumor cells is a method used to determine the biological characteristics and pathogenesis of a tumor, and is important for tissue culture. At present, the molecular mechanisms underlying the pathogenesis, recurrence and metastasis of CRC remain to be elucidated; therefore, the establishment of human CRC cell lines in vitro may provide insight into the biological characteristics and development of CRC. Additionally, the establishment of CRC cell lines provides a convenient and relatively inexpensive cell model for anticancer drug screening. China is a region with high CRC-associated morbidity rates; however, few studies have established CRC cell lines. CRC cell lines derived from China, including THC8908, SIC-8101, HR-8348, Hce8693, HRC-99, DXH-1 and LST-R, have been reported (13-19); the majority of these cell lines are unsuitable for use due to cell contamination or improper storage. Furthermore, other cells lines have not been recorded by internationally recognized institutions for the standardized identification of cell lines. At present, only one CRC cell line, DXH-1, has been reported on the National Experimental Cell Resource Sharing Platform. Therefore, it is important to establish CRC cell lines with a Chinese genetic background to investigate the biological characteristics and pathogenesis of CRC in China.

In the present study, the establishment and characterization of the cc-006cpm8 cell line were conducted. The cell line was analyzed with respect to growth properties, cellular ultrastructure, neoplastic behavior in athymic BALB/c nude mice, karyotype and the expression of tumor-associated antigens; the cell line underwent authentication by short tandem repeat (STR) profiling. Furthermore, the cell cultures were negative for bacteria, fungi and mycoplasma. Exome capture DNA sequencing was performed using the cc- $006 \mathrm{cpm} 8$ cell line to efficiently identify coding variants. The results revealed 20 hypermutated exons comprising single nucleotide polymorphisms (SNPs), and insertion and deletions (InDels) in this cell line, including single nucleotide variants (SNVs) of mucin (MUC) 19, MUC16,MUC12, filaggrin ( $F L G$ ) and AHNAK nucleoprotein 2 (AHNAK2), and InDels of $\beta$ defensin-126 (DEFB126), microRNA-3665 (MIR3665), WNK lysine deficient protein kinase 1 and SLAIN motif-containing 1 (SLAIN1). Additionally, commonly mutated genes in CRC and exon mutations of adenomatous polyposis coli (APC), tumor protein p53 (TP53), Drosophila mothers against decapentaplegic (SMAD)4, phosphatidylinositol-4,5-bisphosphate 3-kinase catalytic subunit $\alpha(P I K 3 C A)$ and Kirsten rat sarcoma (KRAS), in addition to genes of the DNA mismatch-repair (MMR) pathway were determined (20).

\section{Materials and methods}

Tumor origin. Tumor specimens were derived from an 89-year-old Chinese woman treated in the absence of chemotherapy and radiotherapy, and had no family history. The patient had moderately/poorly differentiated right colon invasive ulcerative adenocarcinoma with liver metastasis as stage $4 \mathrm{bN} 1 \mathrm{bM} 1 \mathrm{a}, \mathrm{IV} \mathrm{A}$. The right hemicolectomy of this patient was performed at the Department for Surgical Oncology of Nanjing First Hospital affiliated to Nanjing Medical University (Nanjing, China) in March 16, 2015. Following the surgical procedure, specimens were immediately obtained from primary tumor tissues, and prepared for cell culture and pathological analysis. Informed consent was obtained from the patient and the experiments were approved by the Ethics Committee of Nanjing First Hospital of Nanjing Medical University in accordance with generally accepted guidelines for the use of human material.

Tissue and cell culture. The tumor tissues were immersed in Dulbecco's PBS (DPBS; Gibco; Thermo Fisher Scientific, Inc.) with $1,000 \mathrm{U} / \mathrm{ml}$ penicillin $\mathrm{G}$, $1,000 \mu \mathrm{g} / \mathrm{ml}$ streptomycin and $2.5 \mu \mathrm{g} / \mathrm{ml}$ amphotericin B (DPBS with 10X Antibiotic-Antimycotic). Subsequently, the tumor tissues were washed twice with transport medium and immersed in DPBS with 10X Antibiotic-Antimycotic for 1-2 $\mathrm{h}$ at $4^{\circ} \mathrm{C}$. Following two washes with transport medium, the tissues were ground. The samples were plated in a sterile $6-\mathrm{cm}$ culture dish and cultured in RPMI-1640 supplemented with $10 \%$ heat inactivated fetal bovine serum (both from Gibco; Thermo Fisher Scientific, Inc.) and 1X Antibiotic-Antimycotic (RPMI-1640 complete medium), and maintained in humidified incubators at $37^{\circ} \mathrm{C}$ in an atmosphere of $5 \% \mathrm{CO}_{2}$ and $95 \%$ air. After 2 weeks, the initial cell passage was performed when increased tumor cell growth was observed. Differential trypsinization was used to remove fibroblasts; a pure tumor cell population was obtained comprising the cc-006cp cell line (21).

Subsequently, the monoclonal cell subline derived from the cc-006cp cell line was plated onto semisolid medium. A total of $10^{3}$ viable cc-006cp cells were plated in $3 \mathrm{ml}$ of RPMI-1640 complete medium containing $0.3 \%$ agarose layered over RPMI-1640 complete medium containing $0.5 \%$ agarose; the cells were incubated at $37^{\circ} \mathrm{C}$ with $5 \% \mathrm{CO}_{2}$. Colony formation was observed after 12-15 days, following which single colonies were selected and cultured with RPMI-1640 complete medium in an incubator at $37^{\circ} \mathrm{C}$ with $5 \% \mathrm{CO}_{2}$. Half of the media was replaced every 2-3 days depending on the $\mathrm{pH}$. Using this method, a cell line of high purity and tumorigenicity was successfully derived from human moderately/poorly differentiated colon cancer; the cell line was stably passaged and was designated as cc-006cpm8, which is one of eight sublines of the cc-006cp cell line.

Transmission electron microscopy. For electron microscopy, $1-5 \times 10^{5}$ of the cc- $006 \mathrm{cpm} 8$ cells plated in a $35-\mathrm{mm}$ dish were fixed with $2.5 \%$ glutaraldehyde in $0.1 \mathrm{~mol} / 1$ phosphate buffer for $1 \mathrm{~h}$ at room temperature, and post-fixed with $1 \% \mathrm{OsO}_{4}$ in the aforementioned buffer at $0^{\circ} \mathrm{C}$ for $30 \mathrm{~min}$. The cells were rinsed with the same buffer, dehydrated with ethanol, immersed twice in absolute propylene oxide and embedded in Quetol 812. Sections were cut at a thickness of $100 \mathrm{~nm}$ with a diamond knife and mounted onto grids. Following staining with uranyl acetate and lead citrate, the cells were observed using a JEM-1011 electron microscope at $80 \mathrm{kV}$. 
Chromosome karyotype analysis. The cc-006cpm8 cells were treated with $0.075 \mathrm{~mol} / 1 \mathrm{KCl}$ solution for $20 \mathrm{~min}$ at $37^{\circ} \mathrm{C}$, and then fixed with a solution of methanol: Acetic acid (3:1) solution at $0^{\circ} \mathrm{C}$ for $10 \mathrm{~min}$. Following fixation, the slides were place in trypsin solution ( $0.02 \%$ trypsin $+3 \%$ Tris solution) in a water bath at $37^{\circ} \mathrm{C}$ for $3 \mathrm{~min}$. The cells were then stained with $10 \%$ Giemsa solution for $4 \mathrm{~min}$ at room temperature. The karyotypes of 20 randomly selected cells were analyzed using the GSL 120 Imaging System equipped with Zeiss.

\section{$H \&$ E staining and Wright-Giemsa staining}

$H \&$ Estaining. The patient's tumortissues and the xenografttumors formed by cc-006cpm 8 cells were fixed in $10 \%$ buffered formalin (Thermo Fisher Scientific, Inc.) and processed for permanent paraffin embedding on a Leica ASP 300 tissue processor (Leica Microsystems); 5- $\mu \mathrm{m}$ paraffin sections were stained with hematoxylin and eosin by using a Leica Autostainer XL. These reagents of H\&E staining (code no. 3801698 ) are manufatured by Leica Biosystems Inc. The protocols of modified progressive H\&E stain are presented in Table SI.

Wright-Giemsa staining. The chamber slides of the cc-006cpm8 cells were washed with PBS (pH 6.5), and then placed 3-5 drops of Wright-Giemsa Stain (code no. CO 135; Shanghai BOYAO Biotechnology Inc.) upon the slides for 1-2 min at room temperature, and added 6-10 drops of PBS (pH 6.8) to mix Wright-Giemasa stain for 6-8 min, and the stained slides were then rinsed with water and quickly air-dried.

STR analysis. The cc-006cpm8 cell line, together with the positive and negative controls, were amplified using the GenePrint 10 system (Promega Corporation). The amplified products were then processed using the ABI3730xl Genetic Analyzer (Applied Biosystems; Thermo Fisher Scientific, Inc.). Data were analyzed using GeneMapper4.0 software (Applied Biosystems; Thermo Fisher Scientific, Inc.) and then compared with the American Type Culture Collection (ATCC), Deutsche Sammlung von Mikroorganismen und Zellkulturen (DSMZ) or Japanese Collection of Research Bioresources (JCRB ) databases for reference matching. The STR assay was conducted at the China Center for Type Culture Collection (CCTCC).

In vitro growth properties of cc-006cpm8. For growth curve and population doubling time (PDT) analyses, $1 \times 10^{3}$ cells/well were plated onto 24-well culture plates (Corning Incorporated) and cultured for 8 days in a $\mathrm{CO}_{2}$ incubator. The cells were counted every hour in five wells using a JuLi Stage real-time cell counter. Alterations in cell confluence over time were presented as a growth curve. The PDT of cells in the logarithmic phase was calculated as follows: PDT $=\left(\mathrm{t}-\mathrm{t}_{0}\right)\left[\lg 2 /\left(\operatorname{lgNt}-\lg \mathrm{N}_{0}\right)\right]$ $\left(\mathrm{N}_{0}\right.$ and $\mathrm{Nt}$ represent cell numbers at $\mathrm{t}_{0}$ and $\mathrm{t}$ separately).

To determine the plating efficiency, the cc-006cpm8 cells were plated at various densities, ranging between $1 \times 10^{2}$ and $5 \times 10^{2}$ cells in three replicate $60-\mathrm{mm}$ dishes (Corning ${ }^{\circledR}$ Plastic Culture Dishes; Corning Incorporated). Colonies comprising $>50$ cells were counted 9 days later following staining with $0.5 \%$ crystal violet for $5 \mathrm{~min}$ at $25^{\circ} \mathrm{C}$, and then counted under BX-4 Stereomicroscope (Shanghai Optical Instrument Factory).

cc-006 cpm 8 single cell suspensions $\left(10^{3}\right.$ cells in three replicate $60-\mathrm{mm}$ dishes) with $0.3 \%$ agarose dissolved in
RPMI-1640 complete medium were placed in tissue culture dishes (Corning ${ }^{\circledR}$ Plastic Culture Dishes; Corning Incorporated) on a layer of $0.6 \%$ agarose (in the same medium), which had previously set. The dishes were then transferred to a $37^{\circ} \mathrm{C}$ incubator with $5 \% \mathrm{CO}_{2}$. After 2 weeks, colonies comprising $>50$ cells were counted and the number was divided by 1,000 to determine the colony-forming efficiency. Experiments were conducted in triplicate.

Analysis of tumorigenicity using nude mice. Tumorigenicity was investigated by inoculating $5 \times 10^{6}$ cells/site cc-006cpm8 cells subcutaneously into the shoulder and contralateral hip of five BALB/c male nude mice, which were 4-6 weeks old and weighing 20-25 g, purchased from the Comparative Medical Center of Yangzhou University (Yangzhou, China). All mice were maintained in a HEPA-filtered environment at $24-25^{\circ} \mathrm{C}$ and humidity was maintained at 50-60\%. Observations were conducted at least twice a week via caliper measurements to analyze progressive tumor growth. The study was performed in the Laboratory Animal Center of Southeast University (Nanjing, China), and followed the Constitution of the Laboratory Animal Ethics Committee of Southeast University. The animal experimental ethical inspection form was approved by the Animal Care and Welfare Committee of Southeast University.

Mycoplasma assay. Mycoplasma contamination was assayed using the Myco-PCR-Mix PCR Detection kit (Zhong Qiao). Cell lines should be pre-cultured in the absence of mycoplasma active antibiotics for several days to maximize test sensitivity. Samples should be derived from cultures that are at 90-100\% confluence. Cell culture supernatants can be tested directly without prior preparation. According to the reaction ratio, the sample/Positive Control template/Negative Control template is added respectively to Myco-PCR-Mix in the PCR tubes. The thermal cycler program was as follows: the reaction is started with an initial denaturation for $5 \mathrm{~min}$ at $95^{\circ} \mathrm{C}$; followed by $30 \mathrm{sec}$ at $95^{\circ} \mathrm{C}, 45 \mathrm{sec}$ at $55^{\circ} \mathrm{C}, 45 \mathrm{sec}$ at $72^{\circ} \mathrm{C}$ for 36 cycles; and cooling down to $10^{\circ} \mathrm{C}$. The PCR products were then electrophoresed on $1.5 \%$ agar gel. The results of electrophoresis can be observed directly under ultraviolet light after staining with ethidium bromide (EB). If there is a $250 \mathrm{bp}$ band of sample same to positive control band size, it is indicated that the sample was infected by mycoplasma. This method has been reported to have high sensitivity in the detection of mycoplasma in cell cultures and other cell culture-derived biologicals.

Immunohistochemical (IHC) analysis. The cell line and the original colon cancer tissues were analyzed by immunohistochemistry. The cc-006cpm8 cells were collected by centrifugation at $220 \mathrm{x}$ g for $3 \mathrm{~min}$; the pellets were fixed in $10 \%$ formaldehyde, embedded in paraffin and then sliced into $6-\mu \mathrm{m}$ sections. The sections were stained using the EnVision system. In the original colon cancer tissues, IHC staining was performed on formalin-fixed paraffin-embedded tissues. The paraffin sections were dewaxed in xylene and rehydrated with distilled water. The slides were subsequently incubated with the following antibodies for $60 \mathrm{~min}$ at room temperature: Anti-vimentin (cat. no. MA3-745, Invitrogen; Thermo Fisher Scientific, Inc.; 1:20), anti-pan cytokeratin 

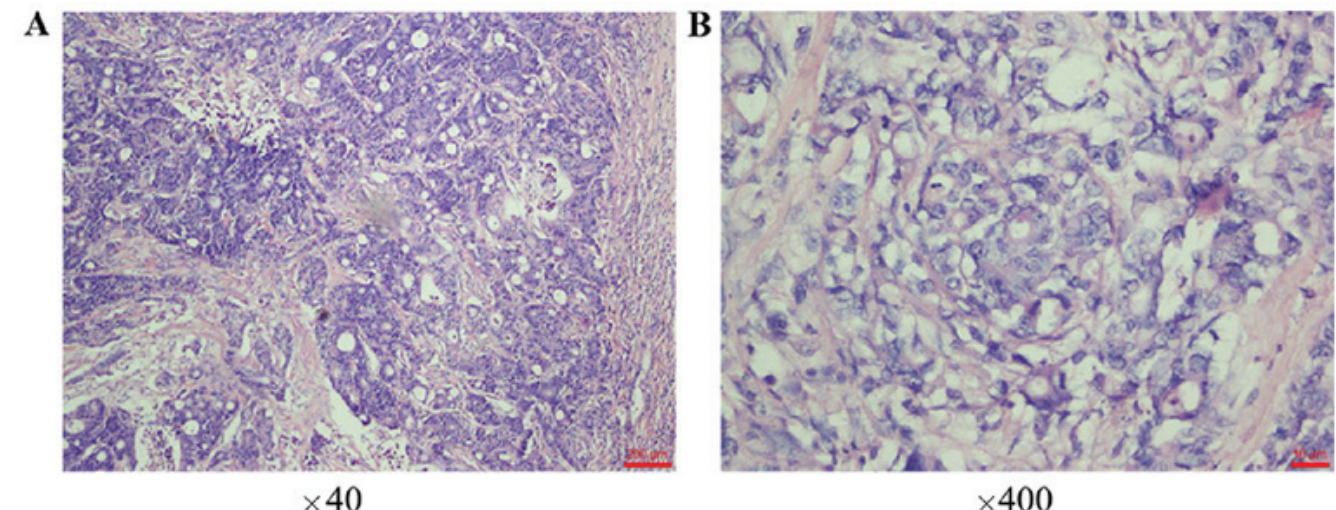

Figure 1. Histology of the primary right colon tumor. H\&E staining of moderately/poorly differentiated primary right colon adenocarcinoma at (A) x40 and (B) X400 magnification.

(cat. no. ab215838; 1:400), anti-epithelial membrane antigen (EMA; cat. no. ab140355; 1:150), anti-carcinoembryonic antigen (CEA; cat. no. ab4451; 1:100) (all from Abcam), anti-p53 (cat. no. sc-47698, Santa Cruz Biotechnology, Inc.; 1:250) and anti-Ki-67 (cat. no. ab8191; 1:50), anti-mucin 2 (cat. no. ab76774; 1:50), anti-caudal type homeobox transcription factor 2 (CDX2; cat. no. ab70458; 1:1,000), anti-mutL homolog 1 (MLH1; cat. no. ab92312; 1:500), anti-mutS protein homolog (MSH2; cat. no ab70270; 1:2,500), anti-mutS homolog 6 (MSH6; cat. no. ab92471; 1:500), anti-postmeiotic segregation 2 (PMS2; cat. no. ab110638; 1:200), anti-BRAF V600E (cat. no. ab200535; $5 \mu \mathrm{g} / \mathrm{ml}$ ) (all from Abcam), anti- $\alpha$-fetoprotein (AFP; cat. no. PA5-11480, Invitrogen; Thermo Fisher Scientific, Inc.; 1:1,0000), anti-glypican-3 (cat. no. ab207080; 1:500), anti-hepatocyte-specific antigen (cat. no. ab75677; 1/1) (both from Abcam). The reaction was performed using Autostainer Link 48 (Dako; Agilent Technologies, Inc.). Secondary antibodies (Dako EnVision+, HRP rab/mouse, K5007; Dako; Agilent Technologies, Inc.) were incubated for $20 \mathrm{~min}$ and 3,3'-diaminobenzidene substrate chromogen counterstaining for $4 \mathrm{~min}$ at room temperature.

For the cell line, the percentage of stained positive cells was scored via a semiquantitative method according to the following scheme: 0 ( $<5 \%$ of tumor cells); $1+(5-25 \%$ of tumor cells); $2+(26-50 \%$ of tumor cells); $3+(51-75 \%$ of tumor cells) and $4+(>75 \%$ of tumor cells). For the tumor tissues, the slides for IHC were observed independently of the diagnosis established from the HES-stained slides. For the slides of colon cancer tissue, the positive index of IHC was determined in regions of high proliferation. Automated detection was conducted using a Dako AutoStainer Link 48. Normal expression was defined as nuclear staining within tumor cells, using infiltrating lymphocytes as the positive internal control. Negative protein expression was defined as the complete absence of staining within tumor cells compared with the positive labeling of internal non-neoplastic tissues.

Flow cytometric analysis. The cc-006cpm8 cells were cultured in a $100-\mathrm{mm}$ plate and then separated by trypsin-EDTA when the cells attained $90 \%$ confluence. Subsequently, the cells were centrifuged at $300 \mathrm{x} \mathrm{g}$ for $10 \mathrm{~min}$ at room temperature and $10^{7}$ cells $/ 100 \mu 1$ were suspended (PBS pH 7.2, 2 mM EDTA and $0.5 \%$ bovine serum albumin; Sigma-Aldrich). The cells were then divided into two groups; one group was stained with human cluster of differentiation 44-fluorescein isothiocyanate (CD44-FITC; cat. no. 130-098-210) and isotype control antibody mouse IgG1-FITC (cat. no. 130-098-847) (both from Miltenyi Biotec) at $4^{\circ} \mathrm{C}$ for $10 \mathrm{~min}$. The other group of cells was stained with human EpCAM-phycoerythrin (CD326-PE; cat. no. 130-098-115) and isotype control antibody mouse IgG1-PE (cat. no. 130-098-845) (both from Miltenyi Biotec) under the same conditions. Analysis was performed with a BD FACSCanto II flow cytometer (BD Biosciences).

Detection of genetic mutations in cc-006cpm8 cells. Exome capture sequencing was performed using the Human Whole-Exon Capture (xGEN ${ }^{\circledR}$ Exome Research Panel) kit of Integrated DNA Technologies and the Illumina Hiseq sequencing platform. The High-Throughput Information Acquisition Technique was used to collect the captured DNA fragments. Each sample produced $10 \mathrm{~Gb}$ clean data on average via the PE150 sequencing strategy. The obtained data were annotated and counted for SNVs and InDels.

\section{Results}

Patient specimens and primary cultures. Dissociated cell suspensions from nine freshly resected colorectal carcinoma tissues of various histological grades were collected for the isolation of cancer cells as aforementioned; two of the specimens were severely contaminated with bacteria and were discarded. A total of five specimens were primary cancer cells derived from a finite population of cells ( $\sim 5-6$ passages) (22). Only two specimens of resected colorectal tumor were used to establish cell lines; one cell line was cc-006cpm8 and was established in the present study for cellular characterization. In addition, the patient was diagnosed with invasive and ulcerative moderately/poorly differentiated adenocarcinoma of the right colon according to postoperative pathology, as demonstrated by H\&E staining of the primary tumor (Fig. 1A and B).

Morphological features and clonal heterogeneity of cc-006cpm8cells. The initial isolation of the primary tumorcells and their propagation in vitro in RPMI-1640 complete medium for 8 days was conducted until those clones were observed. Numerous different cellular shapes and clone morphologies were reported: i) Carcinoma-associated fibroblasts and 
A
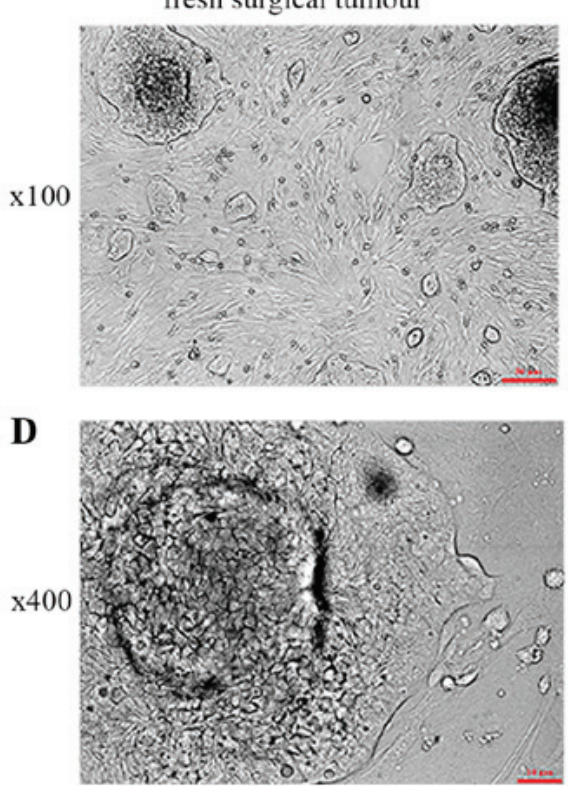

B

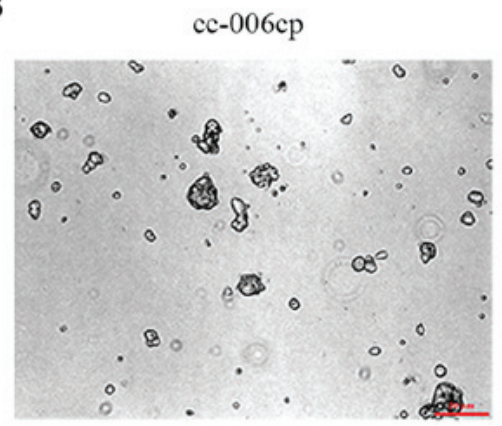

E

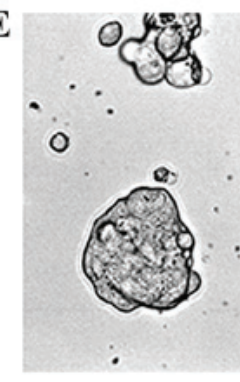

C cc-006 cpm8
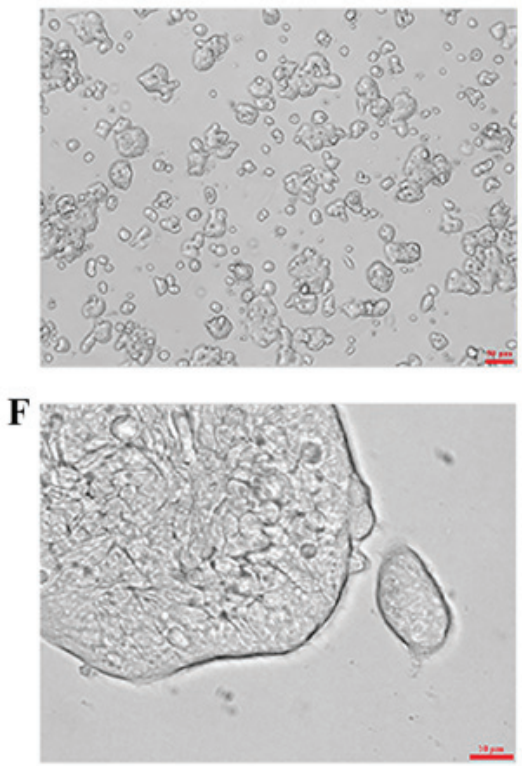

Figure 2. Phase-contrast microscopy analysis of the cellular heterogeneity of the cc-006cpm8 cell line. (A) Clone of cc-006cp surrounded by long fibroblast-like cells with dichotomized processes. (B) Following differential trypsinization, the cc-006cp cell line exhibited an epithelial-like phenotype in the absence of fibroblasts. (C) Following further subcloning, the cc-006cpm8 subline was selected as the monoclonal cell population from the cc-006cp cell line in semisolid medium (magnification, x100). (D) short-term culture at magnification, $\mathrm{x} 400$; (E) cc-006cp at magnification, $\mathrm{x} 400$; (F) cc-006cpm8 subline at magnification, $\mathrm{x} 400$.
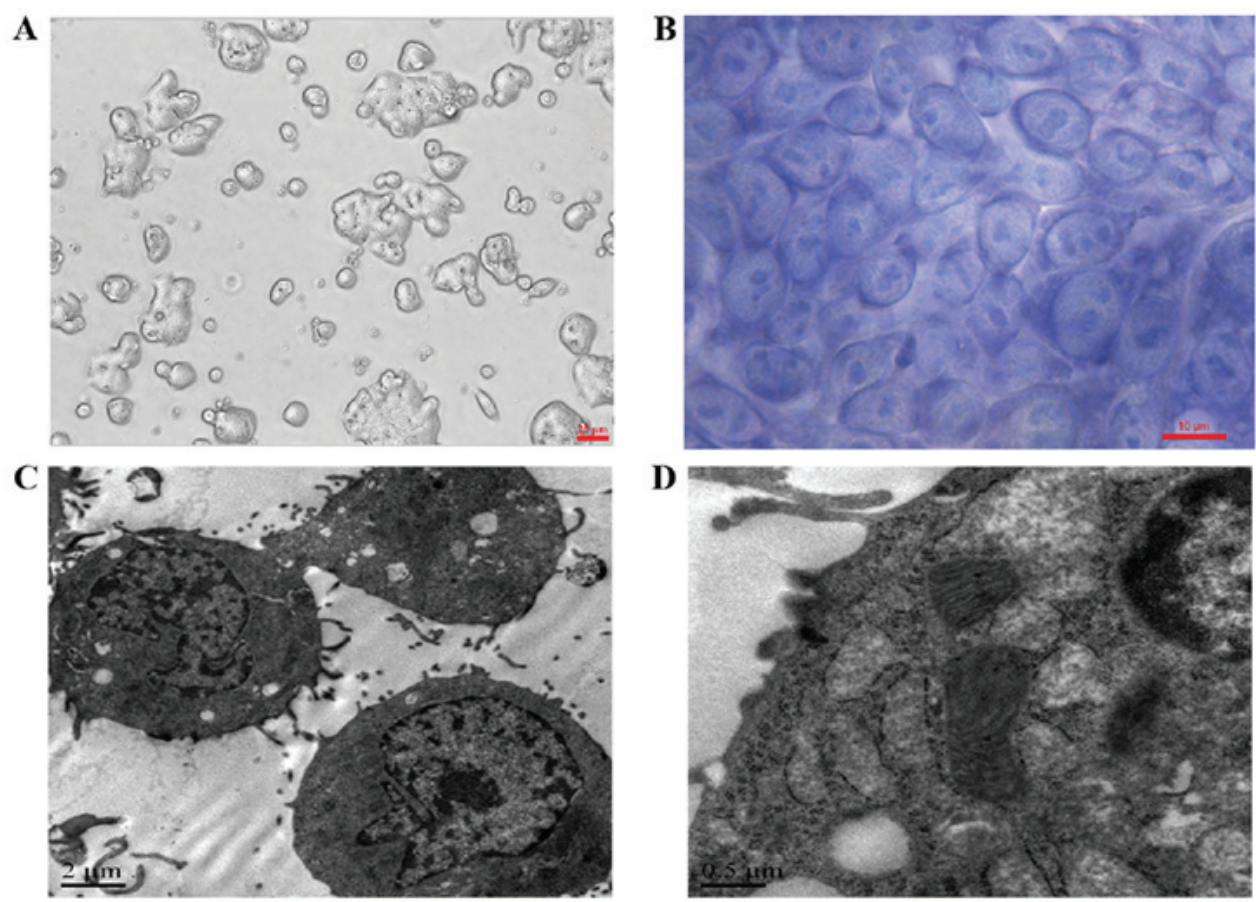

Figure 3. Morphological features of the cc-006cpm8 cell line. (A) Cell morphology was observed under a phase-contrast microscope. Original magnification, x200. (B) In situ Wright's staining of cc-006cpm8 cells. Original magnification, x1,000. Below, electron micrographs show a cell possessing a prominent nucleolus, small irregular microvilli, prominent mitochondria, endoplasmic reticulum and few mucinous granules. Original magnification, (C) x5,000 and (D) 20,000.

normal fibroblasts; ii) sparse large semispheroid clusters with dichotomized processes; and iii) small closely-packed clones (Fig. 2A and D). Following differential trypsinization, the cc-006cp cell line possessed an epithelial phenotype without contaminating fibroblasts; few clones were packed closely together, whereas others were not (Fig. 2B and E), and grew slowly compared with the cc-006cpm8 cell line (Fig. S1).
From further subcloning, cc-006cpm8 cells were selected as the monoclonal cell subline from the cc-006cp cell line in semisolid medium (Fig. 2C and F).

In RPMI-1640 complete medium, the cc- $006 \mathrm{cpm} 8$ cells were cultured as several layers with tight adhesion to the plastic surface and no contact suppression via microscopy (Fig. 3A). Following culture on chamber slides and Wright-Giemsa 

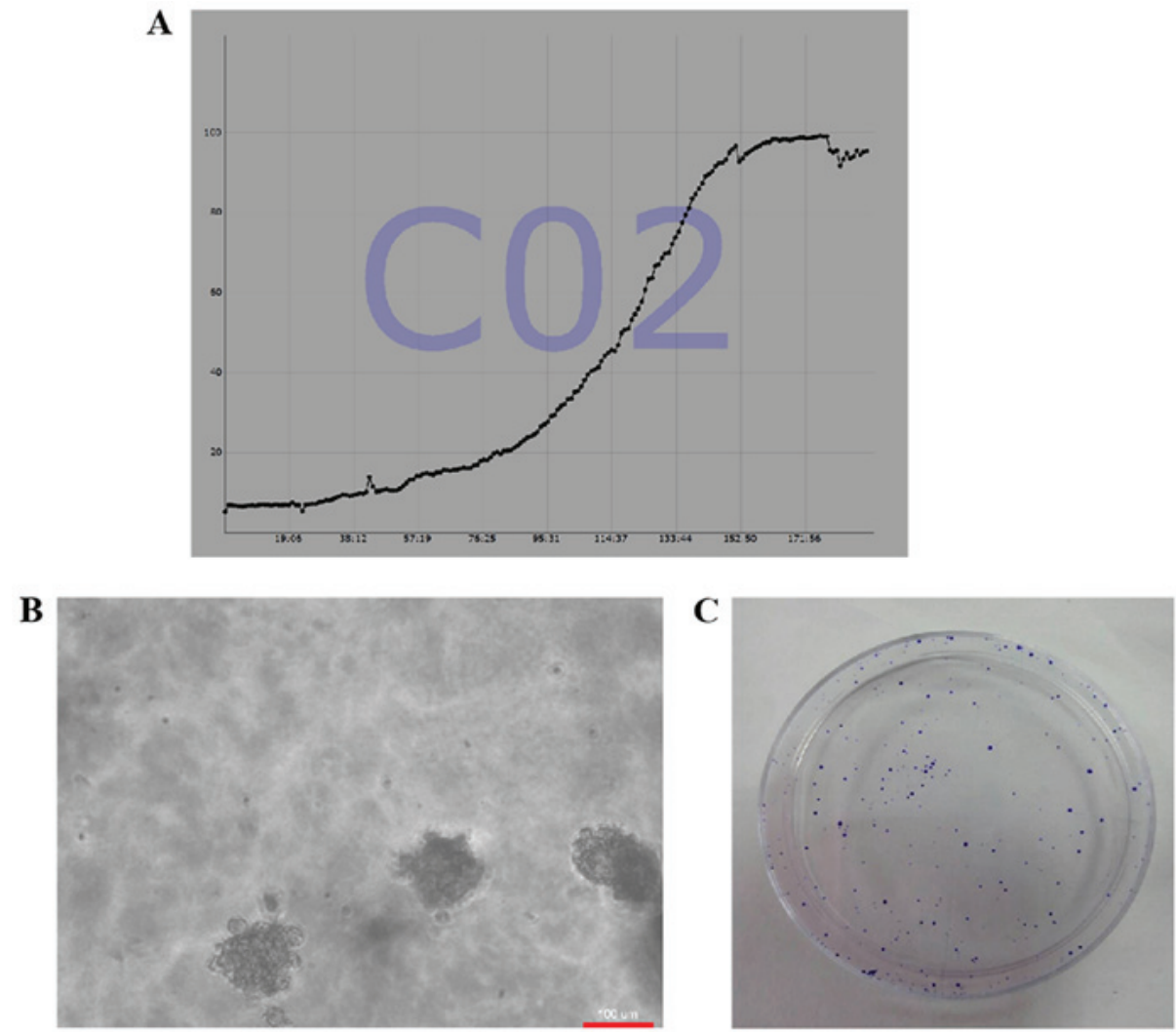

Figure 4. Growth properties of cc-006cpm8 cells in vitro. (A) Growth curve of cc-006cpm8 cells; cells were counted at the indicated time points using a JuLi Stage real-time cell counter. The average population doubling time was $27 \mathrm{~h}$. (B) Cells were cultured in soft agar with a colony-forming efficiency of $73.2 \%$; scale bar, $100 \mu \mathrm{m}$. (C) Plate cloning formation rate was $66.5 \%$.

staining, large nuclei, a thin layer of cytoplasm and numerous nucleoli were observed in the cc-006cpm8 cells via microscopy (Fig. 3B). Under a transmission electron microscope, the cc-006cpm8 cells exhibited a prominent nucleolus, small irregular microvilli, notable mitochondria and endoplasmic reticulum. Few lipid droplets and vacuoles were observed (Fig. 3C and D).

Growth properties of cc-006cpm8 cells in vitro. The cc-006cpm8 cells were passaged continuously $>100$ times over a period of 1 year; the cells exhibited maintained vigorous growth. From the growth curve of the cc-006cpm8 cells, the average PDT was determined to be $27 \mathrm{~h}$ (Fig. 4A). To analyze the proliferation of this cell line, soft agar colony and clone formation assays were performed. The former revealed that the colony formation rate of the cc-006 cpm8 cells was $73.2 \%$ (Fig. 4B) and that of clone formation was $\sim 66.5 \%$; the values of which were obtained from a small number of the 100 cells cultured in 6-mm dishes for 9 days. The resulting clones were stained with crystal violet and colonies constituting $>50$ cells were counted (Fig. 4C). The findings of these assays revealed the proliferative properties of cc-006cpm8 cells.

Tumorigenicity of cc-006cpm8 in vivo. Athymic nude xenograft mice were used in the present study to investigate the tumorigenicity of cc-006cpm8 cells in vivo. Tumor formation was analyzed at least twice a week via caliper measurements; tumors were detected in all mice after 4 weeks (Fig. 5A and B).
These xenograft tumors exhibited similar histology to the primary tumor samples obtained from the patient, as determined by $\mathrm{H} \& \mathrm{E}$ staining (Fig. 5C and D). The xenograft tumor was nodular and adhered to the skin.

Expression of CD326 and CD44. To confirm the origin of the cc-006cpm8 cell line, flow cytometric analysis was performed. The results revealed the proportion of cancer stem cells (CSCs) in the subline. Compared with the control, there were $~ 99.9 \%$ of $\operatorname{EpCAM}(+)$ cells in the cc-006cpm8 population, which suggested that cc-006cpm8 cells were of epithelial origin; however, compared with the control, there were $59.6 \%$ of CD44(+) cells in the cc-006cpm8 population (Fig. 6). The results may indicate that heterogeneous expression was also observed within the same population of cc-006cpm8 cells.

Antigen expression. To confirm the epithelial origin of the cc-006cpm8 cell line associated with the original tumor sections, the expression of keratin and vimentin were investigated via immunocytochemistry. These results demonstrated the positive expression of pan-keratin (Fig. 7A) and negative expression of vimentin (Fig. 7B). These findings suggested the epithelial origin of the cc-006cpm8 cell line. On further observation of the cytokeratin (CK)7/CK20 profile, $\mathrm{CK}^{+} / \mathrm{CK} 20^{-}$expression was present in this cell line and the corresponding original tumor (Fig. S2). Additionally, the expression of certain colon cancer markers in cc-006cpm8 cells and the original tumor sections were determined. Notable positive expression of CDX2 and CEA (Fig. 7C and D), and mucin 2 (Fig. E) was observed. 
A
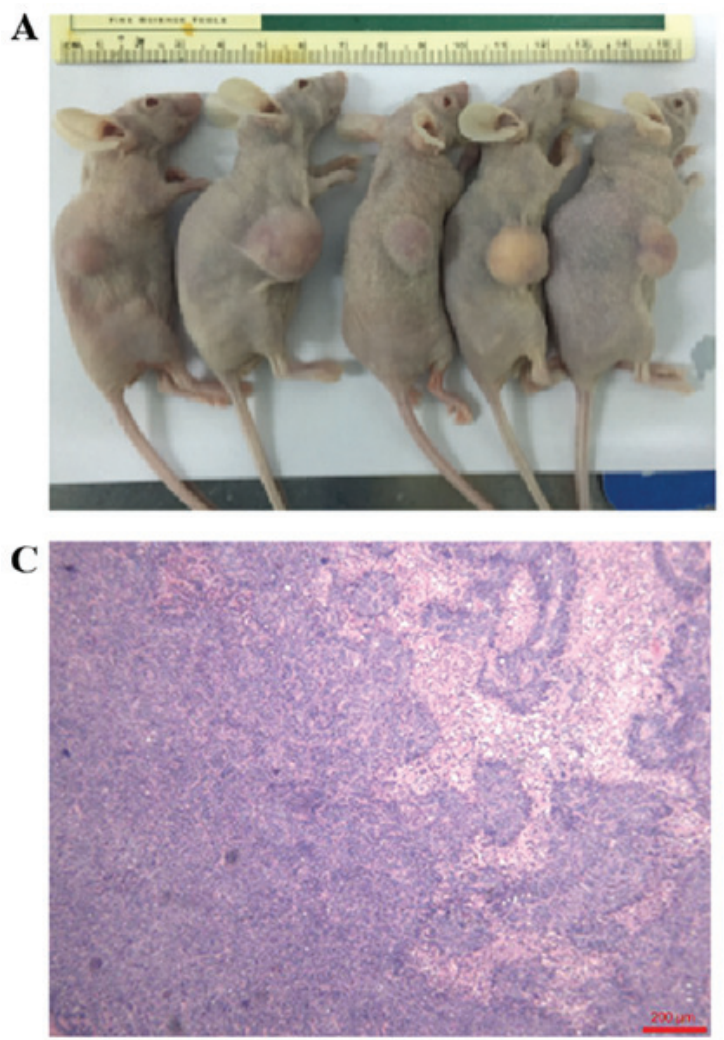

B

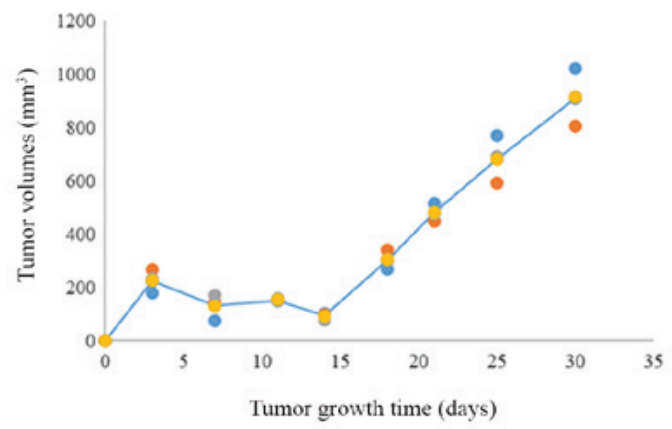

\section{D}

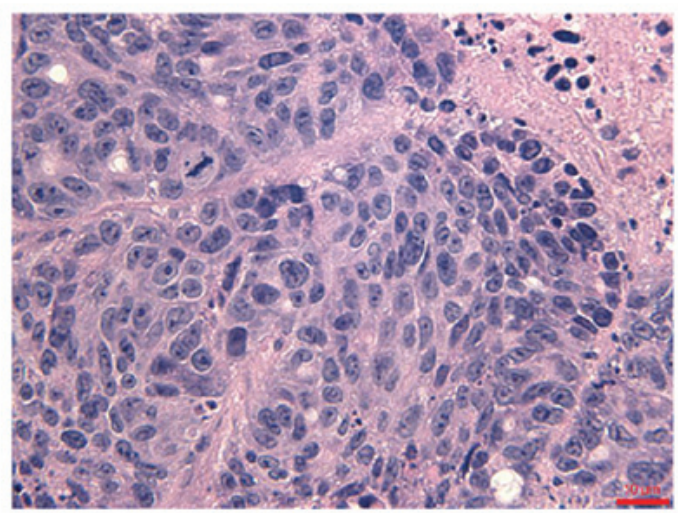

Figure 5. Tumorigenicity of cc- $006 \mathrm{cpm} 8$ cells in vivo. (A) Tumors formed in all five nude mice that were inoculated with $5 \mathrm{x} 10^{6} / \mathrm{site}$ of cc-006cpm 8 cells for 4 weeks. (B) Evaluation of the tumorigenic potential of cc-006cpm8 cells following a subcutaneous injection 4 weeks. H\&E staining of the xenograft tumors formed by cc- $006 \mathrm{cpm} 8$ cells exhibiting moderate/poor differentiation. Magnification, (C) x40 and (D) 400 .

A
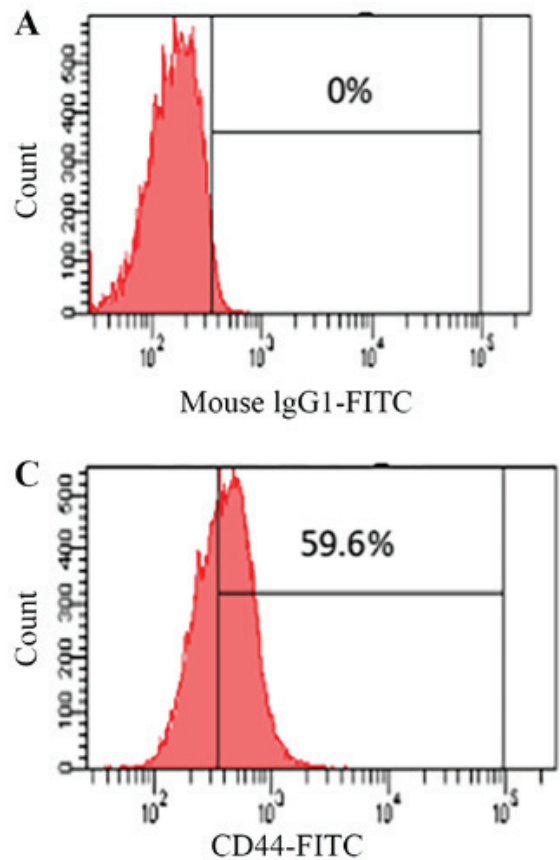
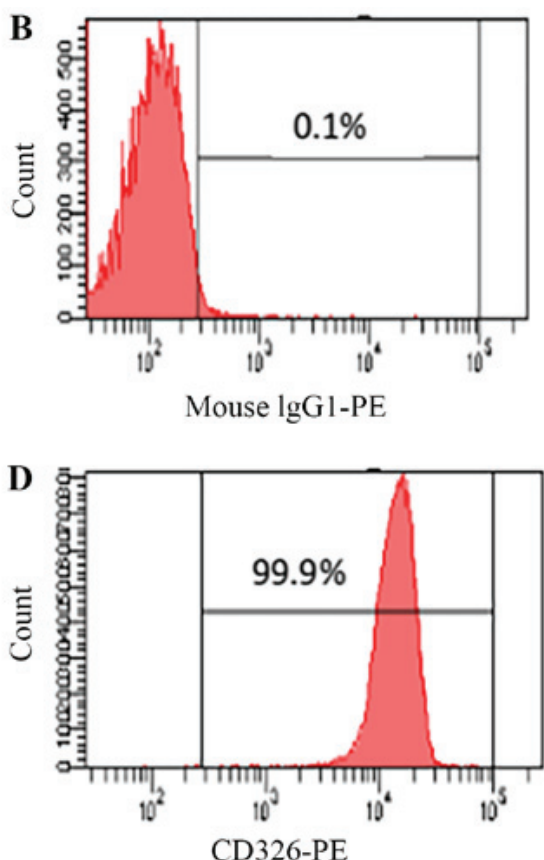

Figure 6. Flow cytometric analysis of the expression of CD44 and CD326. Donkey anti- mouse IgG1 conjugated with (A) FITC or (B) PE were used as the isotype control. Suspended cc-006cpm8 cells were incubated with (C) anti-CD44-FITC or (D) CD326-PE, and were analyzed by flow cytometry. CD, cluster of differentiation; FITC, fluorescein isothiocyanate; PE, phycoerythrin.

Furthermore $50 \%$ of the cells were positively stained for Ki-67 (Fig. 7F); however, negative staining for p53 in the cell line and the tumor sections from the patient was reported (Fig. 7G). In addition, positive staining for EMA was detected in the original tumor sections from the patient. By contrast, the cc- $006 \mathrm{cpm} 8$ cell line exhibited $1 \%$ positive staining (Fig. $7 \mathrm{H}$ ). The results further suggested the biological characteristics and cancer heterogeneity in this cell line. The expression of DNA 
A

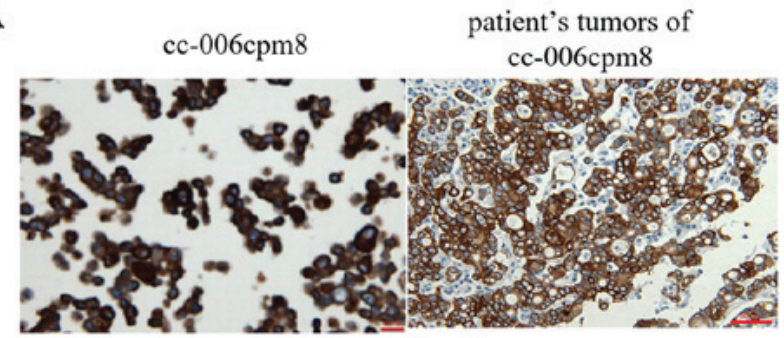

pan-keratin

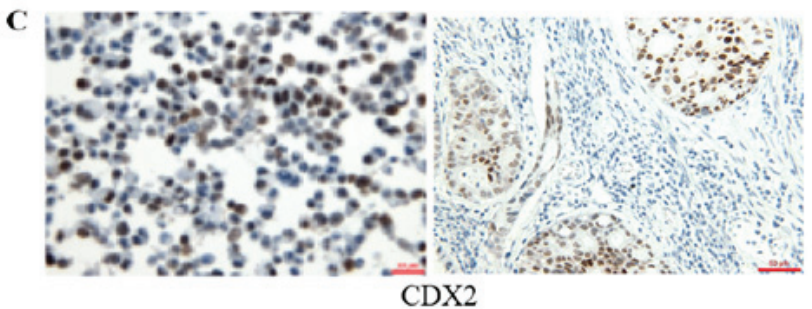

$\mathbf{E}$

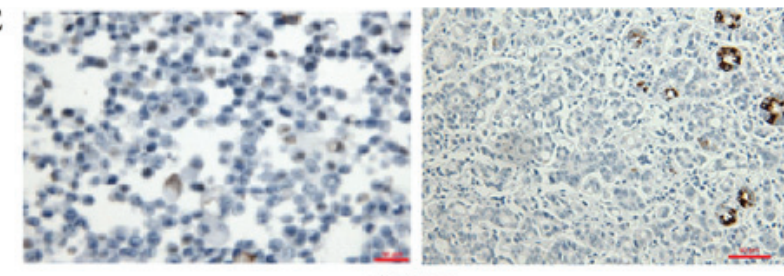

MUC2

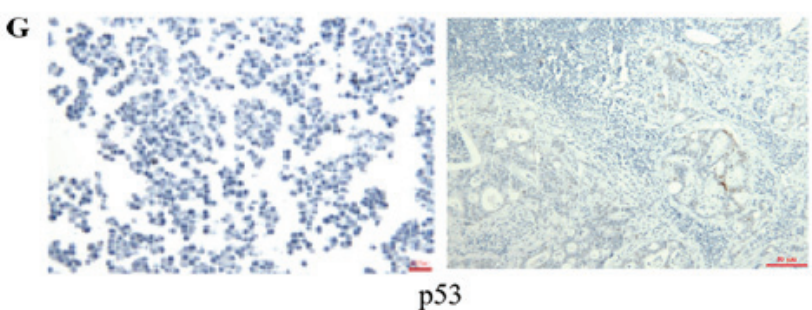

B

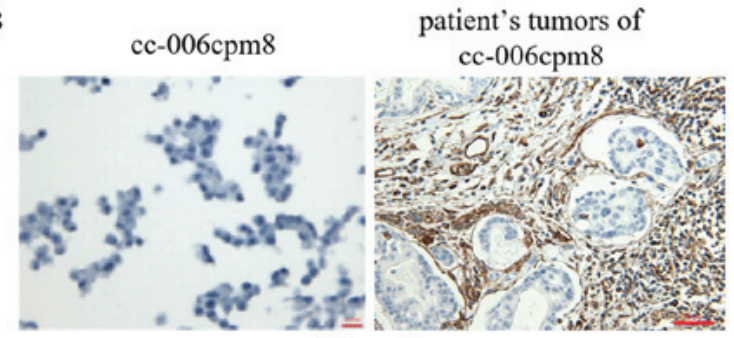

Vimentin

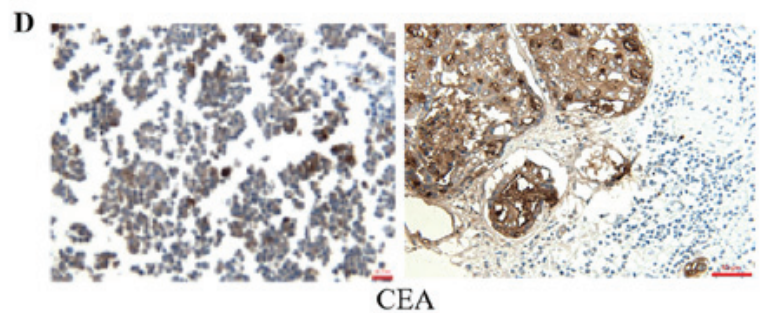

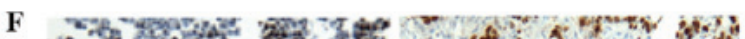

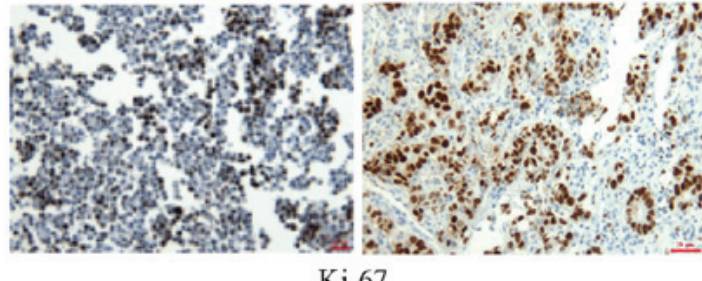

Ki-67

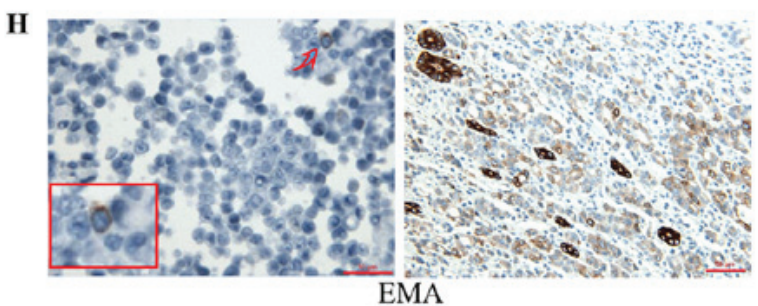

Figure 7. Expression of key colon cancer markers in cc-006cpm8 cells and the original patient tumor sections. Immunohistochemical analysis revealed the expression profile (A) pan-keratin(+++), (C) CDX2(+), (B) vimentin(-), (D) CEA(+++), (E) MUC2(+), (F) Ki-67(++), (G) p53(-) and (H) EMA(-) in cc-006cpm8 cells. $1 \%$ positive staining of EMA (arrows) are shown in high power view in the inset (magnification, $\mathrm{x} 1,000$ ). Protein expression in cc-006cpm8 cells was compared with that of the original patient tumor sections, with the exception of the expression of EMA. Magnification, $\mathrm{x} 400$ (cell line) and 200 (original patient tumor sections). CDX2, caudal type homeobox transcription factor 2; CEA, carcinoem-bryonic antigen; EMA, epithelial membrane antigen; MUC2, mucin 2.

A cc-006cpm8

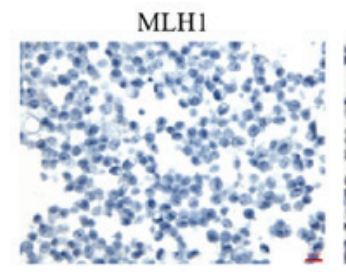

B

Patient tumors of cc-006cpm8
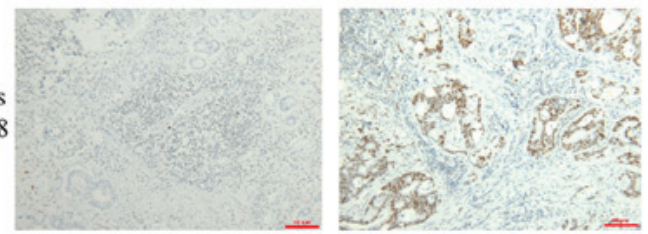

PMS2
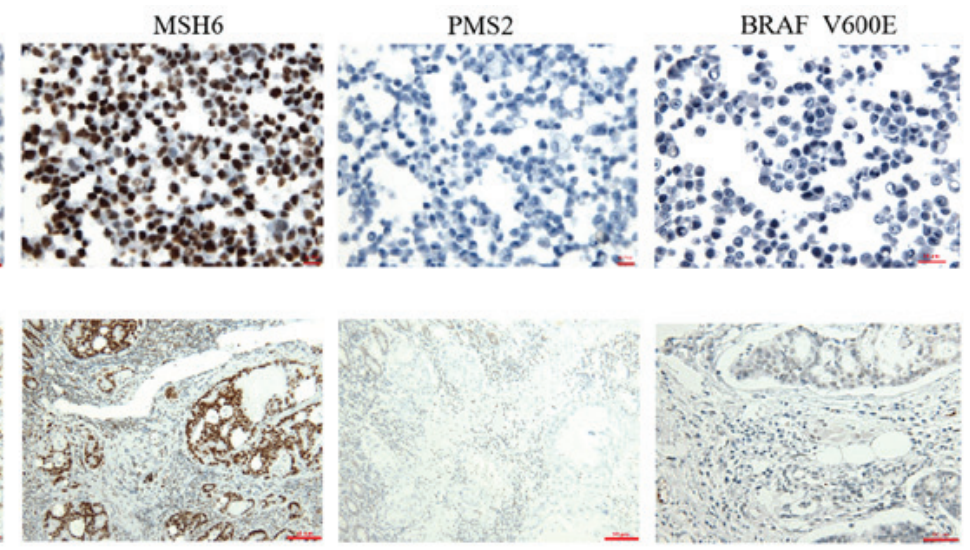

Figure 8. Representative expression of mismatch repair genes in the cc-006cpm8 cell line and the patient tumor sections by immunohistochemical staining. Analysis revealed the expression of MLH1(-), MSH2(++), MSH6(+++), PMS2(-) and BRAF-V600E(+) in the (A) cc-006cpm8 cell line and the (B) patient tumors sections. Magnification, x400 (cells) and 200 (tumor sections). MLH1, mutL homolog 1; MSH2, mutS protein homolog; PMS2, postmeiotic segregation 2.

MMR proteins was also determined by immunocytochemistry in the cell line and the patient tumor sections, respectively. The results revealed the negative expression of MLH1 and PMS2 and notable positive expression of MSH2 and MSH6 (Fig. 8). Within MSI-H colorectal cancer, the BRAF V600E mutation is associated with sporadic tumorigenesis (23). IHC analysis of 
A

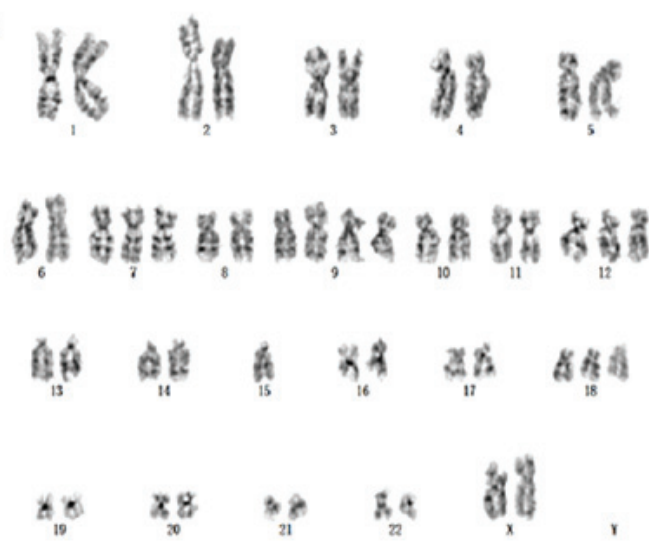

B

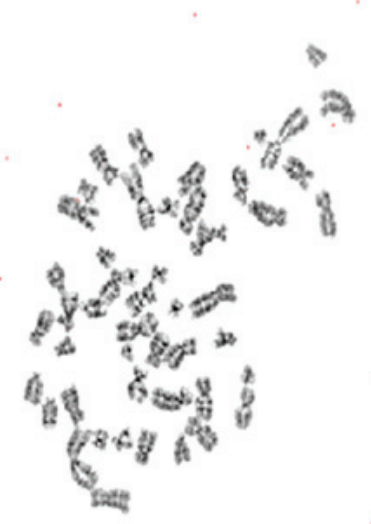

Figure 9. Typical karyotype of the cc-006cpm8 cells. (A) is the karyogram of (B) in the cc-006cpm8 cell. Cc-006cpm8 cell line is a stable hyper-diploid with $84.2 \%$ of the cells possessing a chromosome number of $50 \pm 3$.

Table I. Summary of the whole exon sequencing of the cc-006cpm8 cell line.

\begin{tabular}{lrr}
\hline Term & SNPs (n) & InDels (n) \\
\hline Total & 27,134 & 34,860 \\
Novel & 1,510 & 32,658 \\
Transitions & 20,192 & \\
Transeversions & 7,126 & \\
Homozygous & 10,729 & \\
Heterozygous & 16,362 & \\
Stopgain & 168 & \\
Stoploss & 11 & 208 \\
Missense & 10,556 & 1,621 \\
Frameshift & & 375 \\
Intronic & 7,969 & 9 \\
Intergenic & 3,142 & 12 \\
Splice3 & 10 & 267 \\
Splice5 & 19 & 670 \\
5'-UTRs & 2,119 & \\
3'-UTRs & 2,318 & \\
\hline
\end{tabular}

SNP, single nucleotide polymorphism; InDel, insertion-deletion; UTR, untranslated region.

BRAF V600E in the cell line and the patient tumor sections was performed, and positive expression was reported in the two sample types (Fig. 8). As the specimens were derived from a patient with right colon adenocarcinoma and liver metastasis, the expression of AFP, HepPar-1 and glypican-3 were determined via IHC in the cc-006cpm8 cell and the tumor sections; the antibodies used are those used in the diagnosis of hepatocellular carcinoma. Therefore, this may eliminate the possibility that the cc-006cpm8 cells and patient tumor sections were of hepatic origin as negative expression was reported (Fig. S3).

Chromosomal analysis. Chromosomal analysis of the cc-006cpm8 cell line was performed at passages 5, 10 and 25, in which 20 karyotypes were investigated using Giemsa banding. The results revealed that the modal number of chromosomes in three different passages was similar, indicating chromosomal stability. The modal number of chromosomes in this cell line was 50 , which accounted for $84.2 \%$ of cells; the number of chromosomes ranged between 47 and 53. Therefore, the cell line was reported as hyper-diploid. In cells of passage 10, the karyotypes of the clone with 50 chromosomes were $\mathrm{xx},+7$, $+9,+9,+12,-15$ and +18 (Fig. 9A and B). Other karyotypes were also observed, including $+8,+10,+12,+13,+14,+16,+19$, +21 and $+x$. Collectively, the frequencies of $+7,+8,+9,+12$ and +18 were higher. The results suggested that this cell line was characteristic of malignant tumor cells.

STR analysis. The cc-006cpm8 cell line was subjected to STR profiling by the CCTCC following the ANSI/ATCC ASN-0002-2011, Authentication of Human Cell Lines: Standardization of STR Profiling. The STR analysis of this cell line resulted in unique human profiles, which did not completely match the profiles in the ATCC, DSMZ or JCRB databases, or the National Experimental Resources Cell Sharing Platform.

Detection of genetic mutations in cc-006cpm8 cells. Exome capture DNA sequencing was performed on the cell line; SNVs and InDels were counted from the data. As presented in Table I, 27,134 total SNVs and 34,860 total InDels were reported in the cc-006cpm8 cell line. Among the mutated genes, 1,510 novel SNVs and 32,658 novel InDels were reported. In addition, 20 hypermutated exons containing SNPs and InDels were detected in this cell line, including SNVs of MUC19, MUC16, MUC12, FLG and AHNAK2, and InDels of DEFB126, MIR3665, WNK lysine deficient protein kinase 1 (WNKI) and SLAIN motif-containing 1 (SLAINI) (Fig. 10A and B). Additionally, 24 commonly mutated genes associated with CRC were reported; these mutations may occur in the coding sequences of genes in this cell line(Table II) (20). The genes associated with the DNA MMR pathway were analyzed. $M L H 1$ and MSH6 revealed no mutations; however, $M L H 3, M S H 2, M S H 3$ and PMS2 exhibited missense mutations (24-26). Furthermore, BRAF, APC, TP53, PIK3CA, ERBB2 and TCF7L2 possessed 
Table II. Examples of alterations of coding sequences in the cc-006cpm8 cell line.

\begin{tabular}{|c|c|c|c|}
\hline \multirow[b]{2}{*}{ Classification } & \multirow[b]{2}{*}{ Gene symbol } & \multicolumn{2}{|c|}{ Status of coding sequence } \\
\hline & & SNPs & InDel \\
\hline \multirow[t]{5}{*}{ RTK/RAS pathway } & $K R A S$ & No mutation & No mutation \\
\hline & $N R A S$ & No mutation & No mutation \\
\hline & $B R A F$ & rs9648696 (pE588G), & \\
\hline & & rs113488022 (pV600E) & No mutation \\
\hline & $E R B B 2$ & rs1058808 & No mutation \\
\hline \multirow[t]{3}{*}{ TP53 pathway } & TP53 & rs1042522, & \\
\hline & & rs2287499 (pR68G) & No mutation \\
\hline & $A T M$ & No mutation & rs567403367 \\
\hline \multirow[t]{4}{*}{ TGF- $\beta$ pathway } & SMAD4 & No mutation & No mutation \\
\hline & $S M A D 2$ & No mutation & No mutation \\
\hline & $A C V R 2 A$ & No mutation & No mutation \\
\hline & $T G F B R 2$ & No mutation & rs7937599 \\
\hline IGF2/PI3K pathway & $P I K 3 C A$ & rs121913274 & No mutation \\
\hline \multirow[t]{7}{*}{ MMR pathway } & $M L H 1$ & No mutation & No mutation \\
\hline & $M L H 3$ & rs17102999(pT942I), rs175081(pN826D) & No mutation \\
\hline & MSH2 & rs2303424(pQ915R) & No mutation \\
\hline & MSH3 & rs1650697(pI79V), rs26279(pA1045T), & \\
\hline & & rs184967(pQ949R) & No mutation \\
\hline & MSH6 & No mutation & No mutation \\
\hline & $P M S 2$ & rs2228006 & No mutation \\
\hline \multirow[t]{7}{*}{ WNT pathway } & $A P C$ & rs459552 & $\begin{array}{l}\text { rs387906231, } \\
\text { rs121913334, } \\
\text { rs387906234 }\end{array}$ \\
\hline & $F B X W 7$ & No mutation & No mutation \\
\hline & TCF7L2 & rs77961654 & No mutation \\
\hline & $C T N N B 1$ & No mutation & No mutation \\
\hline & $A R I D I A$ & No mutation & No mutation \\
\hline & $F A M 123 B$ & No mutation & No mutation \\
\hline & SOX9 & No mutation & No mutation \\
\hline
\end{tabular}

SNP, single nucleotide polymorphisms; InDel, insertion-deletion; RTK, receptor tyrosine kinase; RAS, rat sarcoma; KRAS, Kirsten rat sarcoma; TP53, tumor protein p53; ATM, ataxia telangiectasia-mutated; TGF- $\beta$, transforming growth factor- $\beta$; SMAD4, drosophila mothers against decapentaplegic 4; SMAD2, drosophila mothers against decapentaplegic 2; ACVR2A, activin receptor IIA; TGFBR2, transforming growth factor, $\beta$ receptor II; IGF2, insulin-like growth factor 2; PI3K, phosphatidylinositol-3-kinase; MMR, mismatch-repair; MLH1, mutL homolog 1; MLH3, mutL homolog 3; MSH2, mutS homolog 2; MSH3, mutS homolog 3; MSH6, mutS homolog 6; APC, adenomatous polyposis coli; $F B X W 7$, F-box/WD repcat-containing protein 7; TCF7L2, transcription factor 7-like 2; CTNNB1, catenin, $\beta-1 ;$ ARID1A, AT-rich interactive domain-containing protein 1A; SOX9, SRY-related high mobility group box gene 9 .

missense mutations comprising SNPs, and InDels of TGFBR2, $A T M$ and $A P C$, which occurred via frameshift mutations. By contrast, KRAS, NRAS, SMAD4, SMAD2, ACVR2A, FBXW7, CTNNB1, ARID1A, FAM123B and SOX9 exhibited no missense or frameshift mutations in the coding regions.

\section{Discussion}

CRC is a heterogeneous disease. In the present study, a novel cell line (cc-006 cpm8) originating from moderately/poorly differentiated CRC with a Chinese genetic background was established as few have been reported previously. The cc-006cpm8 cells formed an immortal cell line that were passaged $>100$ times in vitro with vigorous growth. This cell line was examined at P0 and P100 respectively by STR analysis and chromosome karyotype analysis. No significant changes were found in either results (data not shown). In addition, this cell line had a relatively high cloning formation rate and rapid growth. Furthermore, the subline was negative for bacteria, fungi and mycoplasma, as determined by PCR. However, further study data on the phenotypic characteristics and the drug resistance of this cell line, and comparison with another colorectal adenocarcinoma cell line, are required. Despite this, the cc-006cpm 8 cell line with clinical biological 
A

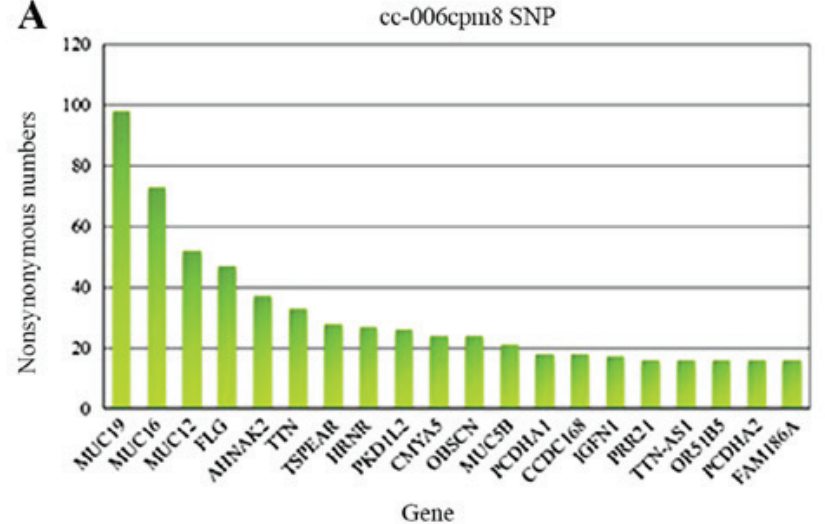

B

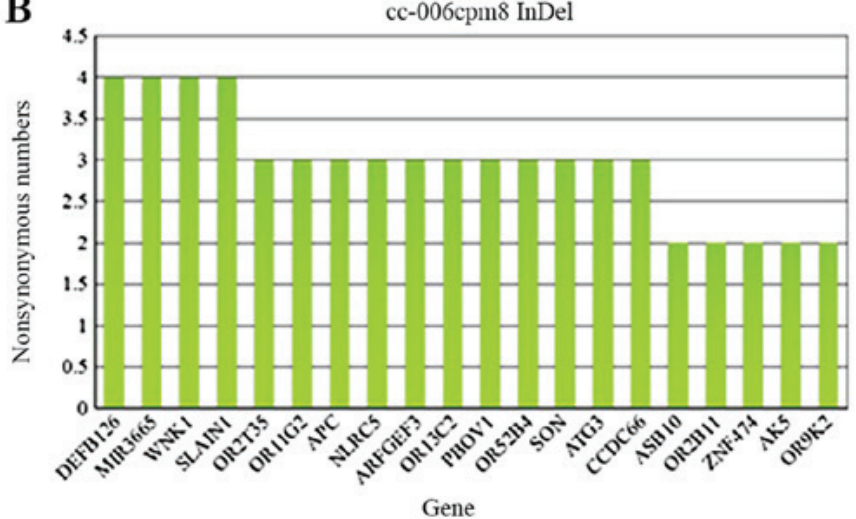

Figure 10. Frequency spectrum of mutated genes in the cc-006cpm8 cell line. Hypermutated exons comprising (A) SNPs and (B) InDels in the cc-006cpm8 cell line. InDels, insertion and deletions; SNP, single nucleotide polymorphisms.

characteristics of CRC may be useful in in vitro and in vivo studies of this disease.

Cell lines can be separated by methods of infinite dilution or plate cloning; however, the cc-006 cpm8 cell line was isolated via semisolid medium in the present study. The soft agar colony formation method is well reported for the analysis of cell proliferative ability (27-33). Usually, the tumor cell colony formation rate is high $(>10 \%)$, whereas that of normal cells is weak ( 0 or $0.05-5 \%)$ in soft agar. In addition, the adhesive and floating properties of tumor cells in liquid culture may contribute to clone formation onto semisolid medium. In addition, these properties inhibit contamination with fibroblasts, which do not form colonies on soft agar. Therefore, this technique may be conducive to the establishment of pure cells lines with similar properties to that of tumor cells in vivo.

Flow cytometric analysis demonstrated that the expression of CD44 was $59.6 \%$ in cc-006 cpm8 cells (a subline of cc-006cp), and the expression of CD44 was $0.1 \%$ in the cc-006cp cell line (data not shown). Further investigation is required to determine the expression levels of additional colorectal CSCs markers, including CD133, CD166 and ALDH1. The cell adhesion molecule CD44 is a hyaluronic acid receptor, which has been suggested as an alternative marker of CSCs. CD44 serves a major role in cancer cell migration, and has been associated with the initiation of tumor development of xenografts and colony formation, in addition to tumor stage, lymph node infiltration, and patient prognosis and survival $(34,35)$. To determine the epithelial origin, the expression of EpCAM cell surface markers was analyzed and reported to be $99.9 \%$ in cc-006cpm8 cells. EpCAM, a similar protein to CD44, known for its role in cell adhesion, may have versatile roles in signaling, cell migration, proliferation and differentiation (36).

The cc-006cpm 8 cell line associated with the original tumor sections exhibited a $\mathrm{CK}^{+} / \mathrm{CK} 20^{-}$expression profile. In general, the $\mathrm{CK} 7 / \mathrm{CK} 20^{+}$profile is known to be characteristic of CRC (37-41); however, not all CRCs exhibit this profile. A substantial proportion of $\mathrm{CRC}$ are reported to be either $\mathrm{CK} 7^{+}$ or CK20, particularly in right-sided and high-grade CRCs, consisting of poorly differentiated adenocarcinoma (PDA) and undifferentiated carcinoma, among others (42). Imai et al reported that $\mathrm{CK} 20^{-} \mathrm{PDA}$ significantly favored solid type (Por1) de novo histogenesis, and a smaller proportion of stromal tissue. By contrast, $\mathrm{CK} 20^{+}$PDA significantly favored non-solid type (Por2) histogenesis in stepwise de-differentiation, and higher levels of stromal tissue (43). The expression of CDX2 may be a useful adjunct for the diagnosis of intestinal adenocarcinomas. In the present study, notable positive expression of CDX2 was shown by IHC staining of the cell line and corresponding original tumor. CDX2 represents the latest in a series of transcription factors that have been reported to have important applications in diagnostic surgical pathology as specific and sensitive markers of specific cell and tumor types (44). Among colorectal adenocarcinomas, the association between tumor grade and CDX2 staining has been controversial. Hinoi et al (45) demonstrated that a rare subset of poorly differentiated colonic carcinomas, termed large cell minimally differentiated carcinoma or medullary carcinoma, are characterized by microsatellite instability and loss of CDX2 expression. Kaimaktchiev et al (46) examined 1,109 tissue microarray samples of colorectal adenocarcinomas and found a lack of CDX2 reactivity in 14 (28\%) of 50 poorly differentiated tumors.

The present study reported that the cc- $006 \mathrm{cpm} 8$ cell line exhibited negative expression of MLH1 and PMS2 via IHC; MLH1 possessed no SNPs or InDel mutations in the coding region, as determined by whole exome capture DNA sequencing. This may be due to the abnormal hypermethylation of the $M L H 1$ promoter, which prevents gene transcription (47). $M L H 1$ is one of the DNA MMR genes associated with Lynch syndrome. This disorder is caused by germline mutations of the MMR genes, including MLH1, MLH2, MLH6 and PMS2 (48). MSI-H CRC may exist in 2-3\% Lynch syndrome and $15 \%$ sporadic CRC cases. The patient enrolled in the present study was 89 years old and had no family history. According to the Bethesda and revised Bethesda criteria (49), the patient was determined to have Lynch syndrome. In addition, within MSI-H CRC, the BRAF V600E mutation has been associated with sporadic tumorigenesis (23). Therefore, IHC for BRAF V600E in the cell line and patient tumor sections was conducted; the cells and tissues exhibited notable positive expression. Collectively, the aforementioned findings further support that the patient possessed sporadic CRC rather than Lynch syndrome. 
From the results of genetic mutation detection in the present study, a frequency spectrum of mutated genes in the cc-006cpm8 cell line was obtained (Fig. 10A and B). Numerous gene mutations occurred with high frequencies, including SNPs of MUC19, MUC16, MUC12, FLG and AHNAK2, and InDels of DEFB126, MIR3665, WNK1 and SLAIN1. Mucins are glycoproteins encoded by the MUC genes. There are four categories of mucins: Transmembrane (TM), secreted gel forming, secreted non-gel forming and unclassified mucins. MUC19 is a secreted gel forming mucin gene (50). At present, investigations into the association between MUC19 and CRC remain limited. MUC12 is a TM mucin and has been reported as a novel mucin gene associated with membranes (51). It has been suggested that TM mucins promote tumor invasion (52). MUC12 is widely known to be downregulated in CRC $(51,53)$. Matsuyama et al (54) reported that the mRNA expression of MUC12 is an independent prognostic marker of stage II and III CRC. Patients with low expression levels of MUC12 exhibited poor disease-free survival. Therefore, the high-frequency mutation of MUC12 may be associated with the poor prognosis of patients with CRC. With a low expression of MUC12, patients may present with poorer disease-free survival. MUC16 was first identified from the molecular cloning of CA125 in 2001 (55). MUC16 also belongs to the TM class of mucins and is the largest of its type (56). In addition, MUC16 serves as a biomarker for ovarian cancer worldwide (57); however, MUC16 has also been detected in other types of cancer, including pancreatic and gastric cancer, and colorectal adenocarcinomas. Zhang et al (58) reported the detection of CA125 (MUC16) as an effective diagnostic marker of CRC. For $F L G$, few investigations have been conducted. Skaaby et al (59) proposed that there were no statistically significant associations between the loss-of-function mutation of $F L G$ and sporadic types of cancer, such as CRC. Therefore, mutations of $F L G$ in CRC require further investigation. At present, the association between $A H N A K 2$ and CRC has not been determined; however, AHNAK2 has been revealed to be a prognostic biomarker for clear cell renal cell carcinoma and pancreatic ductal adenocarcinoma $(60,61)$. Additionally, Wen et al (62) reported $A H N A K 2$ as a susceptibility gene for systemic lupus erythematosus; however, mutations of DEFB126, MIR3665, WNK1 and SLAIN1 were not associated with CRC according to previous studies. Therefore, further investigation into the role of high-frequency gene mutations in the cc-006cpm8 cell line for the development of CRC is required.

In conclusion, a novel stable cell line of moderately/poorly differentiated CRC (cc-006cpm8) of Chinese genetic background was generated in the present study. The cc-006cpm8 cells were well characterized as a cell line and may be useful for the investigation of $\mathrm{CRC}$ in the future.

\section{Acknowledgements}

The authors would like to thank Professor Wenbin Huang from the Department of Pathology of Nanjing First Hospital for IHC analysis and Professor Xiuqing Ji from the Genetic Medicine Center of Maternity Hospital attached to Nanjing Medical University for chromosomal analysis.

\section{Funding}

The present study was partly supported by grants from the National Natural Science Foundation of China (grant nos. 81572928 and 81772978) and the Jiangsu Provincial Special Program of Medical Science (grant no. BE2017611) to JC.

\section{Availability of data and materials}

The datasets used and analyzed during this study are available from the corresponding author on reasonable request.

\section{Authors' contributions}

$\mathrm{XC}$ analyzed and interpreted the results of the detection of this novel cell line, and wrote a part of the manuscript. YX performed identification of the cell line, and was a major contributor in writing the manuscript. $\mathrm{XH}$ was responsible for specimen collection. JW wrote part of the manuscript and modified the images and was involved in data processing. YC and RH performed the cell culture. HC and XS produced the pathological sections. HZ organized the data for all the experiments. YG provided useful interpretation of the genetic mutations data. JC conceived and designed and supervised the study. All authors have read and approved the final manuscript.

\section{Ethics approval and consent to participate}

For the use of patient sample, the patient signed informed consent forms for the use of their sample in scientific research. The experiments were approved by the Ethics Committee of Nanjing First Hospital of Nanjing Medical University.

\section{Patient consent for publication}

Not applicable.

\section{Competing interests}

The authors declare that they have no competing interests.

\section{References}

1. Ferlay J, Soerjomataram I, Dikshit R, Eser S, Mathers C, Rebelo M, Parkin DM, Forman D and Bray F: Cancer incidence and mortality worldwide: Sources, methods and major patterns in GLOBOCAN 2012. Int J Cancer 136: E359-E386, 2015.

2. GLOBOCAN: Estimated cancer incidence, mortality and prevalence worldwide in 2012. 2012. http://globocan.iarc.fr/Default. aspx.

3. Bray F, Ferlay J, Laversanne M, Brewster DH, Gombe Mbalawa C, Kohler B, Piñeros M, Steliarova-Foucher E, Swaminathan R, Antoni S, et al: Cancer Incidence in Five Continents: Inclusion criteria, highlights from Volume $\mathrm{X}$ and the global status of cancer registration. Int J Cancer 137: 2060-2071, 2015.

4. Torre LA, Siegel RL, Ward EM and Jemal A: Global cancer incidence and mortality rates and trends - an update. Cancer Epidemiol Biomarkers Prev 25: 16-27, 2016.

5. Siegel RL, Miller KD and Jemal A: Cancer statistics, 2015. CA Cancer J Clin 65: 5-29, 2015.

6. Worthley DL, Whitehall VL, Spring KJ and LeggettBA: Colorectal carcinogenesis: Road maps to cancer. World J Gastroenterol 13: 3784-3791, 2007.

7. Arends MJ: Pathways of colorectal carcinogenesis. Appl Immunohistochem Mol Morphol 21: 97-102, 2013. 
8. Barrasa JI, Olmo N, Lizarbe MA and Turnay J: Bile acids in the colon, from healthy to cytotoxic molecules. Toxicol In Vitro 27: 964-977, 2013

9. Tariq K and Ghias K: Colorectal cancer carcinogenesis: A review of mechanisms. Cancer Biol Med 13: 120-135, 2016.

10. Tejpar S and Van Cutsem E: Molecular and genetic defects in colorectal tumorigenesis. Best Pract Res Clin Gastroenterol 16: $171-185,2002$.

11. Fakih MG: Metastatic colorectal cancer: Current state and future directions. J Clin Oncol 33: 1809-1824, 2015.

12. Nagahashi M, Wakai T, Shimada Y, Ichikawa H, Kameyama H, Kobayashi T, Sakata J, Yagi R, Sato N, Kitagawa Y, et al: Genomic landscape of colorectal cancer in Japan: Clinical implications of comprehensive genomic sequencing for precision medicine. Genome Med 8: 136, 2016.

13. Liu HY, Li C, Wang LM, Yang Y, Zhan ZL and Zhang TZ: Establishment and characterization of a cell line THC-8908 from human well differentiated colon adenocarcinoma. Chin J Clin Oncol 20: 330-333, 1993

14. Fu ZM: Establishment and characteristics of a human colon adenocarcinoma cell line (SIC-8101). Chin J Clin Oncol 13 47-49, 1986.

15. Zhang ZX, Xu SH and Qian LJ: Establishment and characterization of a cell line HR-8348 derived from human poorly differentiated adenocarcinoma of rectum. Sci Sin B 30: 522-532, 1987.

16. Zhang XZ: Establishment and characterization of a cell line Hce-8693 from human undifferentiated caecal adenocarcinoma. Zhonghua Zhong Liu Za Zhi 11: 413-415, 1989 (In Chinese).

17. Zheng XL, Zhou ZG, Gu J, Li HG, Lin L and Deng YL: Establishment and characterization of a cell line HRC-99 from human rectal adenocarcinoma. World Chin J Digestology 13 1510-1513, 2005

18. Ding KF, Hu YT, Xiao Q, He JJ and Zheng S: A cell line DXH-1 from human colon carcinoma and its application. CN Patent CN201510631287.2. Filed September 29, 2015; issued February 3, 2016.

19. Wang XY, Lai ZS, Yeung CM, Wang JD, Deng W, Li HY, Han YJ, Kung HF, Jiang B and Lin MC: Establishment and characterization of a new cell line derived from human colorectal laterally spreading tumor. World J Gastroenterol 14: 1204-1211, 2008

20. Cancer Genome Atlas Network: Comprehensive molecular characterization of human colon and rectal cancer. Nature 487: 330-337, 2012

21. Brattain MG, Brattain DE, Fine WD, Khaled FM, Marks ME Kimball PM, Arcolano LA and Danbury BH: Initiation and characterization of cultures of human colonic carcinoma with different biological characteristics utilizing feeder layers of confluent fibroblasts. Oncodev Biol Med 2: 355-366, 1981.

22. Peeh DM: Are primary cultures realistic models of prostate cancer? J Cell Biochem 91: 185-195, 2004.

23. Capper D, Voigt A, Bozukova G, Ahadova A, Kickingereder P, von Deimling A, von Knebel Doeberitz $\mathrm{M}$ and Kloor M: BRAF V600E-specific immunohistochemistry for the exclusion of Lynch syndrome in MSI-H colorectal cancer. Int J Cancer 133: 1624-1630, 2013

24. Aaltonen LA, Peltomäki P, Leach FS, Sistonen P, Pylkkänen L, Mecklin JP, Järvinen H, Powell SM, Jen J, Hamilton SR, et al: Clues to the pathogenesis of familial colorectal cancer. Science 260: 812-816, 1993.

25. Ionov Y, Peinado MA, Malkhosyan S, Shibata D and Perucho M: Ubiquitous somatic mutations in simple repeated sequences reveal a new mechanism for colonic carcinogenesis. Nature 363: 558-561, 1993

26. Parsons R, Li GM, Longley MJ, Fang WH, Papadopoulos N, Jen J, de la Chapelle A, Kinzler KW, Vogelstein B and Modrich P: Hypermutability and mismatch repair deficiency in $\mathrm{RER}^{+}$tumor cells. Cell 75: 1227-1236, 1993.

27. Tsukamoto Y, Fumoto S, Noguchi T, Yanagihara K, Hirashita Y, Nakada C, Hijiya N, Uchida T, Matsuura K, Hamanaka R, et al: Expression of DDX27 contributes to colony-forming ability of gastric cancer cells and correlates with poor prognosis in gastric cancer. Am J Cancer Res 5: 2998-3014, 2015.

28. Ercan D, Choi HG, Yun CH, Capelletti M, Xie T, Eck MJ, Gray NS and Jänne PA: EGFR mutations and resistance to irreversible pyrimidine based EGFR receptors. Clin Cancer Res 21: 3913-3923, 2015

29. Mayr C, Wagner A, Stoecklinger A, Jakab M, Illig R, Berr F, Pichler M, Di Fazio P, Ocker M, Neureiter D, et al: 3-Deazaneplanocin A may directly target putative cancer stem cells in biliary tract cancer. Anticancer Res 35: 4697-4705, 2015
30. Hua G, Lv X, He C, Remmenga SW, Rodabough KJ, Dong J, Yang L, Lele SM, Yang P, Zhou J, et al: YAP induces high-grade serous carcinoma in fallopian tube secretory epithelial cells. Oncogene 35: 2247-2265, 2016

31. Ukaji T, Lin Y, Banno K, Okada S and Umezawa K: Inhibition of IGF-1 mediated cellular migration and invasion by migracin A in ovarian clear cell carcinoma cells. PLoS One 10: e0137663, 2015.

32. Bon H, Wadhwa K, Schreiner A, Osborne M, Carroll T, Ramos-Montoya A, Ross-Adams H, Visser M, Hoffmann R, Ahmed AA, et al: Salt-inducible kinase 2 regulates mitotic progression and transcription in prostate cancer. Mol Cancer Res 13: 620-635, 2015

33. Kim T, Jeon YJ, Cui R, Lee JH, Peng Y, Kim SH, Tili E, Alder H and Croce CM: Role of MYC-regulated long noncoding RNAs in cell cycle regulation and tumorigenesis. J Natl Cancer Inst 107: dju505, 2015.

34. Dou J and Gu N: Emerging strategies for the identification and targeting of cancer stem cells. Tumour Biol 31: 243-253, 2010.

35. Horst D, Kriegl L, Engel J, Kirchner T and Jung A: Prognostic significance of the cancer stem cell markers CD133, CD44, and CD166 in colorectal cancer. Cancer Invest 27: 844-850, 2009.

36. Lugli A, Iezzi G, Hostettler I, Muraro MG, Mele V, Tornillo L, Carafa V, Spagnoli G, Terracciano L and Zlobec I: Prognostic impact of the expression of putative cancer stem cell markers CD133, CD166, CD44s, EpCAM, and ALDH1 in colorectal cancer. Br J Cancer 103: 382-390, 2010.

37. Varadhachary GR, Abbruzzese JL and Lenzi R: Diagnostic strategies for unknown primary cancer. Cancer 100: 1776-1785, 2004.

38. Moll R, Löwe A, Laufer J and Franke WW: Cytokeratin 20 in human carcinomas. A new histodiagnostic marker detected by monoclonal antibodies. Am J Pathol 140: 427-447, 1992.

39. Loy TS and Calaluce RD: Utility of cytokeratin immunostaining in separating pulmonary adenocarcinomas from colonic adenocarcinomas. Am J Clin Pathol 102: 764-767, 1994

40. Wauters CC,Smedts F, Gerrits LG, Bosman FT and Ramaekers FC: Keratins 7 and 20 as diagnostic markers of carcinomas metastatic to the ovary. Hum Pathol 26: 852-855, 1995.

41. Chu P, Wu E and Weiss LM: Cytokeratin 7 and cytokeratin 20 expression in epithelial neoplasms: A survey of 435 cases. Mod Pathol 13: 962-972, 2000

42. Park SY, Kim HS, Hong EK and Kim WH: Expression of cytokeratins 7 and 20 in primary carcinomas of the stomach and colorectum and their value in the differential diagnosis of metastatic carcinomas to the ovary. Hum Pathol 33: 1078-1085, 2002.

43. Imai Y, Yamagishi H, Fukuda K, Okamura T, Ono Y, Ban S, Inoue $\mathrm{T}$ and Ueda Y: Expression of cytokeratin 20 indicates invasive histological phenotype in poorly differentiated colorectal adenocarcinoma. Anticancer Res 34: 159-167, 2014.

44. Bayrak R, Haltas $H$ and Yenidunya S: The value of CDX2 and cytokeratins 7 and 20 expression in differentiating colorectal adenocarcinomas from extraintestinal gastrointestinal adenocarcinomas: Cytokeratin $7 / 20^{+}$phenotype is more specific than CDX2 antibody. Diagn Pathol 7: 9, 2012.

45. Hinoi T, Tani M, Lucas PC, Caca K, Dunn RL, Macri E, Loda M, Appelman HD, Cho KR and Fearon ER: Loss of CDX2 expression and microsatellite instability are prominent features of large cell minimally differentiated carcinomas of the colon. Am J Pathol 159: 2239-2248, 2001

46. Kaimaktchiev V, Terracciano L, Tornillo L, Spichtin H, Stoios D, Bundi M, Korcheva V, Mirlacher M, Loda M, Sauter G, et al: The homeobox intestinal differentiation factor CDX2 is selectively expressed in gastrointestinal adenocarcinomas. Mod Pathol 17: 1392-1399, 2004

47. Jasperson KW, Tuohy TM, Neklason DW and Burt RW: Hereditary and familial colon cancer. Gastroenterology 138: 2044-2058, 2010

48. Strate LL and Syngal S: Hereditary colorectal cancer syndromes. Cancer Causes Control 16: 201-213, 2005.

49. Macrae F, Harris M, Massimo R and Alberto M: Re: Revised Bethesda Guidelines for hereditary nonpolyposis colorectal cancer (Lynch syndrome) and microsatellite instability. J Natl Cancer Inst 97: 936-937, author reply 937-938, 2005.

50. Senapati S, Sharma P, Bafna S, Roy HK and Batra SK: The MUC gene family: Their role in the diagnosis and prognosis of gastric cancer. Histol Histopathol 23: 1541-1552, 2008

51. Williams SJ, McGuckin MA, Gotley DC, Eyre HJ, Sutherland GR and Antalis TM: Two novel mucin genes down-regulated in colorectal cancer identified by differential display. Cancer Res 59: 4083-4089, 1999. 
52. Hollingsworth MA and Swanson BJ: Mucins in cancer: Protection and control of the cell surface. Nat Rev Cancer 4: 45-60, 2004.

53. Packer LM, Williams SJ, Callaghan S, Gotley DC and McGuckin MA: Expression of the cell surface mucin gene family in adenocarcinomas. Int J Oncol 25: 1119-1126, 2004.

54. Matsuyama T, Ishikawa T, Mogushi K, Yoshida T, Iida S, Uetake H, Mizushima H, Tanaka $\mathrm{H}$ and Sugihara K: MUC12 mRNA expression is an independent marker of prognosis in stage II and stage III colorectal cancer. Int J Cancer 127: 2292-2299, 2010.

55. Yin BW and Lloyd KO: Molecular cloning of the CA125 ovarian cancer antigen: Identification as a new mucin, MUC16. J Biol Chem 276: 27371-27375, 2001.

56. Kufe DW: Mucins in cancer: Function, prognosis and therapy. Nat Rev Cancer 9: 874-885, 2009.

57. Yin BW, Dnistrian A and Lloyd KO: Ovarian cancer antigen CA125 is encoded by the MUC16 mucin gene. Int J Cancer 98 737-740, 2002

58. Zhang B, Liang XL, Gao HY, Ye LS and Wang YG: Models of logistic regression analysis, support vector machine, and back-propagation neural network based on serum tumor markers in colorectal cancer diagnosis. Genet Mol Res: May 13, 2016 (Epub ahead of print). doi: 10.4238/gmr.15028643.
59. Skaaby T, Husemoen LL, Thyssen JP, Meldgaard M, Thuesen BH, Pisinger C, Jørgensen T, Carlsen K, Johansen JD, Menné T, et al: Filaggrin loss-of-function mutations and incident cancer: A population-based study. Br J Dermatol 171: 1407-1414, 2014.

60. Wang M, Li X, Zhang J, Yang Q, Chen W, Jin W, Huang YR, Yang R and Gao WQ: AHNAK2 is a novel prognostic marker and oncogenic protein for clear cell renal cell carcinoma. Theranostics 7: 1100-1113, 2017.

61. Lu D, Wang J, Shi X, Yue B and Hao J: AHNAK2 is a potential prognostic biomarker in patients with PDAC. Oncotarget 8: 31775-31784, 2017.

62. Wen L, Zhu C, Zhu Z, Yang C, Zheng X, Liu L, Zuo X, Sheng Y, Tang H, Liang B, et al: Exome-wide association study identifies four novel loci for systemic lupus erythematosus in Han Chinese population. Ann Rheum Dis 77: 417, 2018. 